\title{
An Assessment of Dietary and Physical Activity Behaviours of Adolescents in Selected Secondary Schools in Guyana

\author{
L Stephanas
}

\begin{abstract}
Background: In Guyana, the five leading causes of death are ischaemic heart disease, cerebrovascular disease, cancer, diabetes mellitus and hypertension. Maintaining healthy eating habits and adequate daily physical activity could prevent many of these conditions.

Objective: The purpose of this study was to examine the dietary and physical activity behaviours of adolescents in selected secondary schools in Guyana.

Methods: A cross-sectional Youth Physical Activity and Nutrition Survey was conducted in 12 secondary schools; two schools from each of the coastal regions $2-6$ and Georgetown, the capital city of Guyana; 724 students in Forms one to four participated. A National Youth Physical Activity and Nutritional Survey (NYPANS) tool was used for data collection. Height and weight were measured using standard protocols. Descriptive and inferential statistics $95 \%$ confidence intervals and Chi-square test were computed using SPSS IBM 20.

Results: Fifty-four per cent of students reported participating in physical activity that made them sweat and breathe hard for at least 20 minutes on three or more of the previous seven days. Almost half (48.7\%) of the students played video or computer games for one or more hours on an average school day and $56.3 \%$ of students reported not attending physical education (PE) classes at all school. Only $12.6 \%$ and $12.9 \%$ of students reported eating two or more cups of fruit and vegetables, respectively each day.

Conclusion: Results from this study reveal that participation in healthy dietary and physical activity behaviours among adolescents in selected secondary schools of Guyana, is far from optimal.
\end{abstract}

Keywords: Adolescents, childhood, diet, nutrition, physical activity

\section{Evaluación de los Comportamientos de la Actividad Física y Dietética de los Adolescentes en las Seleccionados Escuelas Secundarias de Guyana}

\author{
L Stephanas
}

\begin{abstract}
RESUMEN
Antecedentes: En Guyana, las cinco causas principales de muerte son: cardiopatía isquémica, enfermedad cerebrovascular, cáncer, diabetes mellitus, e hipertensión. Mantener hábitos alimenticios saludables y actividad física cotidiana adecuada podría evitar muchas de estas condiciones.

Objetivo: El propósito de este estudio fue examinar los comportamientos en relación con la actividad fisica y dietética de los adolescentes en las escuelas secundarias de Guyana.

Métodos: Se realizó una encuesta transversal sobre la actividad fisica y la nutrición de los jóvenes en 12 escuelas secundarias: dos escuelas de cada una de las regiones costeras y
\end{abstract}

From: Department of Public Health, Faculty of Heath Sciences, University of Guyana.
Correspondence: Dr L Stephanas, Top Flat, $100 \mathrm{~A}, 6^{\text {th }}$ Street, Cummings Lodge, East Coast Demerara, Georgetown, Guyana, South America. Email: lois.stephanas@gmail.com 
Georgetown, la capital de Guyana. La encuesta contó con la participación de 724 estudiantes de $7^{\circ}$ a $10^{\circ}$ grado. Una herramienta de la Encuesta Nacional sobre la Actividad Física y la Nutrición de los Jóvenes (NYPANS, siglas en inglés fue utilizada para la recolección de datos. El peso y la altura fueron medidos utilizando protocolos estándar. Los intervalos de confianza del 95\% de la estadistica descriptiva e inferencial y Chi Cuadrado se computaron mediante SPSS IBM 20.

Resultados: Cincuenta y cuatro por ciento de los estudiantes reportaron su participación en actividades fisicas que les hacian sudar y respirar fuerte durante al menos 20 minutos en tres o más de los anteriores siete días. Casi la mitad (48.7\%) de los estudiantes se entretenían con vídeos o juegos de computadoras por una o más horas en un día normal de escuela, y 56.3\% de los estudiantes reportaron no asistir a clases de educación física (EF) en la escuela en lo absoluto. Sólo $12.6 \%$ y $12.9 \%$ de los estudiantes reportaron comer dos o más tazas de frutas y vegetales respectivamente todos los días.

Conclusión: Los resultados de este estudio revelan que la participación en actividades físicas $y$ dietas saludables entre los adolescentes en las escuelas secundarias de Guyana selecciona, dista mucho de ser óptima.

Palabras claves: Adolescentes, infancia, dieta, nutrición, actividad física

West Indian Med J 2017; 66 (2): 251

\section{INTRODUCTION}

In a world where so many things seem out of hand, taking control of what one eats is an important personal way to affect how one feels. Fundamental knowledge about nutrition can make a tremendous contribution to one's level of wellness. It can help to make food choices that will enhance health and vitality. Food not only sustains life but also has a clear link to disease prevention. It is a scientifically proven fact that certain foods [especially fruits and vegetables and whole grains] are directly associated with prevention of cardiovascular diseases and certain cancer-leading causes of death (1).

Schools are in a unique position to promote healthy eating and help ensure appropriate food and nutrient intake among students. Schools provide students with opportunities to consume an array of foods and beverages throughout the school day and enable students to learn about and practice healthy eating behaviours. Schools should ensure that only nutritious and appealing foods and beverages are provided in school cafeterias, vending machines, snack bars, school stores and other venues that offer food and beverages to students. In addition, nutrition education should be part of a comprehensive school health education curriculum (2).

According to the World Health Organization (WHO), non-communicable diseases (NCDs) are estimated to account for $66 \%$ of all deaths of all ages. Out of $66 \%$, deaths due to cardiovascular disease (CVD) are $36 \%$, cancers $8 \%$, diabetes $8 \%$, respiratory diseases $2 \%$, other NCDs $12 \%$. Deaths under the age of 60 years due to NCDs in 2008 were in males (37.7\%) and females (35.2\%). Age-standardized death rate per 100000 population due to all NCDs is 735 in males and 602.4 in females and specifically due to cardiovascular diseases and diabetes is 475.2 in males and 427.8 in females. There is no currently operational topic specific policy/ programme/action plan for cardiovascular diseases, diabetes, unhealthy diet/overweight/ obesity and physical inactivity (3).

\section{SUBJECTS AND METHODS}

A quantitative, cross-sectional design was utilized to examine dietary and physical activity behaviours of secondary school children in Guyana. This survey was conducted in two (2) selected secondary schools in each of the coastal regions (2-6) and Georgetown of Guyana.

Systematic stratified random sampling technique was used to draw a required sample size from respective selected secondary schools. Sample size was 724 participants, 60 each from 12 schools, with the exception of Lenora secondary school, where an additional four students from Form one were willing to be part of the survey and were included.

Data were collected using A National Youth Physical Activity and Nutritional Survey (NYPANS) tool which was developed by the experts in nutrition from the Centers for Disease Control (CDC) experts in nutrition, 
physical activity, health promotion and epidemiology. It was modified and was utilized.

This study was first approved by the Faculty of Health Sciences, University of Guyana and later by University of Guyana Council. Permission to collect the data in selected secondary schools was sought and received from Chief Education Officer, Ministry of Education. Later, research proposal was submitted to Institutional Review Board of Ministry of Health. Approval to conduct the study was given by chief medical officer (CMO), Ministry of Health.

Using SPSS stats descriptive statistics, number, percentage, means, standard deviation and inferential statistics $95 \%$ confidence intervals (CI) and Chi-square test were computed to analyse the data.

The percentage shown in $\mathrm{N}[\%]$ style is $=\mathrm{N} \times 100$ / [total number of students in that category with valid answers]. Ninety-five per cent CI represents $95 \%$ confidence interval of the percentage value.

\section{RESULTS}

A vast majority of students (93.92\%) were between 12 and 15 years of age. Students were near-evenly distributed with respect to gender; females $(55.4 \%)$ were slightly more than males $(44.61 \%)$. Students were evenly distributed with respect to Grade level: $25 \%$ each from Form one to Form four. The majority $(69.9 \%)$ of students were Christians; 289 (39.9\%) participants identified themselves as Africans, 216 (29.8\%) were mixed and $174(24.0 \%)$ were of East-Indian decent; $28.2 \%$ of students indicated a family income between G\$35 000 60000 per month and $26.4 \%$ students indicated less than G\$35000 per month. Generally, students expressed lack of knowledge to answer this question; $30.3 \%$ of the students reported earning A grades and $41.0 \%$ reported earning $\mathrm{B}$ grades in previous classes.

Body mass index (BMI) was calculated for each student using the formula:

$$
\mathrm{BMI}=\text { weight in } \mathrm{kg} /{\text { [height in meter }{ }^{2}}^{2}
$$

The Data Table of BMI-for-age Charts by CDC (4) was used to find out the $5^{\text {th }}$ percentile, $85^{\text {th }}$ percentile and $95^{\text {th }}$ percentile BMI value corresponding to each student's age and gender. In accordance with BMI: Considerations for Practitioners - CDC, each student's BMI was compared to the percentiles [corresponding to the student's age and gender] to derive student's BMI classification.

Out of 724 students, 496 [68.5\%] had normal BMI, $22 \%$ of students were underweight, $6.2 \%$ were overweight and $3.3 \%$ were obese. Only $44.3 \%$ of students had correct perception of their weight and $50.8 \%$ of students had taken appropriate measures to control their weight.

Table 1: Correlation of body mass index classification with gender, age, form level and ethnicity in selected secondary school youth in the coastal regions of Guyana, 2013/2014

\begin{tabular}{|c|c|c|c|c|c|c|c|c|c|c|c|c|}
\hline \multirow[t]{2}{*}{ Characteristics } & \multicolumn{3}{|c|}{ Underweight } & \multicolumn{3}{|c|}{ Normal } & \multicolumn{3}{|c|}{ Overweight } & \multicolumn{3}{|c|}{ Obese } \\
\hline & $\mathbf{N}[\%]$ & $95 \% \mathrm{CI}$ & $\chi^{2}[\mathbf{d f}]$ & $\mathbf{N}[\%]$ & $95 \%$ CI & $\chi^{2}[\mathbf{d f}]$ & $\mathbf{N}[\%]$ & $95 \%$ CI & $\chi^{2}[\mathbf{d f}]$ & $\mathbf{N}[\%]$ & $95 \%$ CI & $\chi^{2}[\mathbf{d f}]$ \\
\hline \multicolumn{13}{|l|}{ Gender } \\
\hline Female & 78 [19.5] & $15.6-23.3$ & $3.3[1]$ & 283 [70.8] & $66.1-75.1$ & $1.8[1]$ & $29[7.2]$ & $4.7-9.8$ & $1.6[1]$ & $11[2.7]$ & $1.1-4.3$ & $0.9[1]$ \\
\hline \multicolumn{13}{|l|}{ Age } \\
\hline 12 & 43 [26.1] & $19.3-32.8$ & & 111 [67.3] & $60.0-74.5$ & & $10[6.1]$ & $2.4-9.7$ & & $1[0.6]$ & $-0.6-1.8$ & \\
\hline 13 & 44 [23.3] & $17.2-29.4$ & & 129 [68.3] & $61.6-74.9$ & & $9[4.8]$ & $1.7-7.8$ & & $7[3.7]$ & $1.0-6.4$ & \\
\hline 16 & $10[24.4]$ & $10.7-38.1$ & & $29[70.7]$ & $56.2-85.3$ & & $1[2.4]$ & $-2.5-7.4$ & & $1[2.4]$ & $-2.5-7.4$ & \\
\hline \multicolumn{13}{|l|}{ Grade level } \\
\hline Form 1 & 46 [24.7] & $18.5-31.0$ & & 127 [68.3] & $61.6-75.0$ & & 11 [5.9] & $2.5-9.3$ & & $2[1.1]$ & $-0.4-2.6$ & \\
\hline Form 2 & 41 [22.9] & $16.7-29.1$ & & $120[67.0]$ & $60.1-74.0$ & & 12 [6.7] & $3.0-10.4$ & & $6[3.4]$ & $0.7-6.0$ & \\
\hline Form 3 & 31 [17.4] & $11.8-23.0$ & $3.1[3]$ & $124[69.7]$ & $62.8-76.5$ & $0.3[3]$ & $13[7.3]$ & $3.4-11.2$ & $0.9[3]$ & $10[5.6]$ & $2.2-9.0$ & $5.9[3]$ \\
\hline Form 4 & 41 [22.7] & $16.5-28.8$ & & $125[69.1]$ & $62.3-75.9$ & & $9[5.0]$ & $1.8-8.2$ & & $6[3.3]$ & $0.7-5.9$ & \\
\hline Other [mixed] & $52[24.1]$ & $18.3-29.8$ & & $141[65.3]$ & $58.9-71.7$ & & 15 [6.9] & $3.5-10.4$ & & $8[3.7]$ & $1.2-6.2$ & \\
\hline Total & $159[22.0]$ & 18.9-25.1 & & $496[68.5]$ & 63.3-73.7 & & $45[6.2]$ & 4.4-8.0 & & $24[3.3]$ & $2.0-4.6$ & \\
\hline
\end{tabular}




\section{DISCUSSION}

The present study shows that about one in every five assessed students is in the category of underweight, in accordance with CDC standards of BMI classification. This calls for preventive measures to be taken in order to control and maintain normal body mass index. More boys than girls were found to be underweight. Significantly, more East-Indian students were underweight.

Current study reveals that about half (54\%) the assessed students participated in vigorous activity and less than half $(38 \%)$ of them exercised to strengthen or tone muscles, such as push-ups, sit-ups, or weight lifting. These estimates are lower than the Florida middle school youth estimates of $72.3 \%$ who participated in sufficient vigorous physical activity and $33.6 \%$ participated in sufficient moderate physical activity (5). This might be due to lack of structured physical activity programmes and unavailability of sports equipment and sports facilities in the school in Guyana.

The present study found that more than half of the students reported not attending PE classes at all at school on an average week. Contrastingly, Zapata et al (5) found that in Florida about half of middle school students attended PE classes daily, and less than half reported not going to PE classes at all during the average school week. However, the present study found that more girls reported not attending PE classes than boys which is consistent with previous study findings (5). This might be due to girls tending to gather together and talk rather than play. An important note: teachers of participating schools reported lack of facilities such as play grounds, sports equipment, qualified personnel, which could be the reason for not having PE classes in their schools.

More than half of the assessed students reported watching DVDs or videos and TV, respectively for one or more hours on an average school day. More boys reported watching DVDs and videos than the girls. More students of African origin reported watching TV for one or more hours than the students of other ethnic groups, Brener et al (6) found that "female and black students engaged in less physical activity and spent more time watching DVDs or videos than did male and white students". Olivares et al (8) found that about a half of Chilean youth (12-13-year old) watched TV one to two hours a day.

The current study reveals that the majority of students reported walking and running/jogging during the 


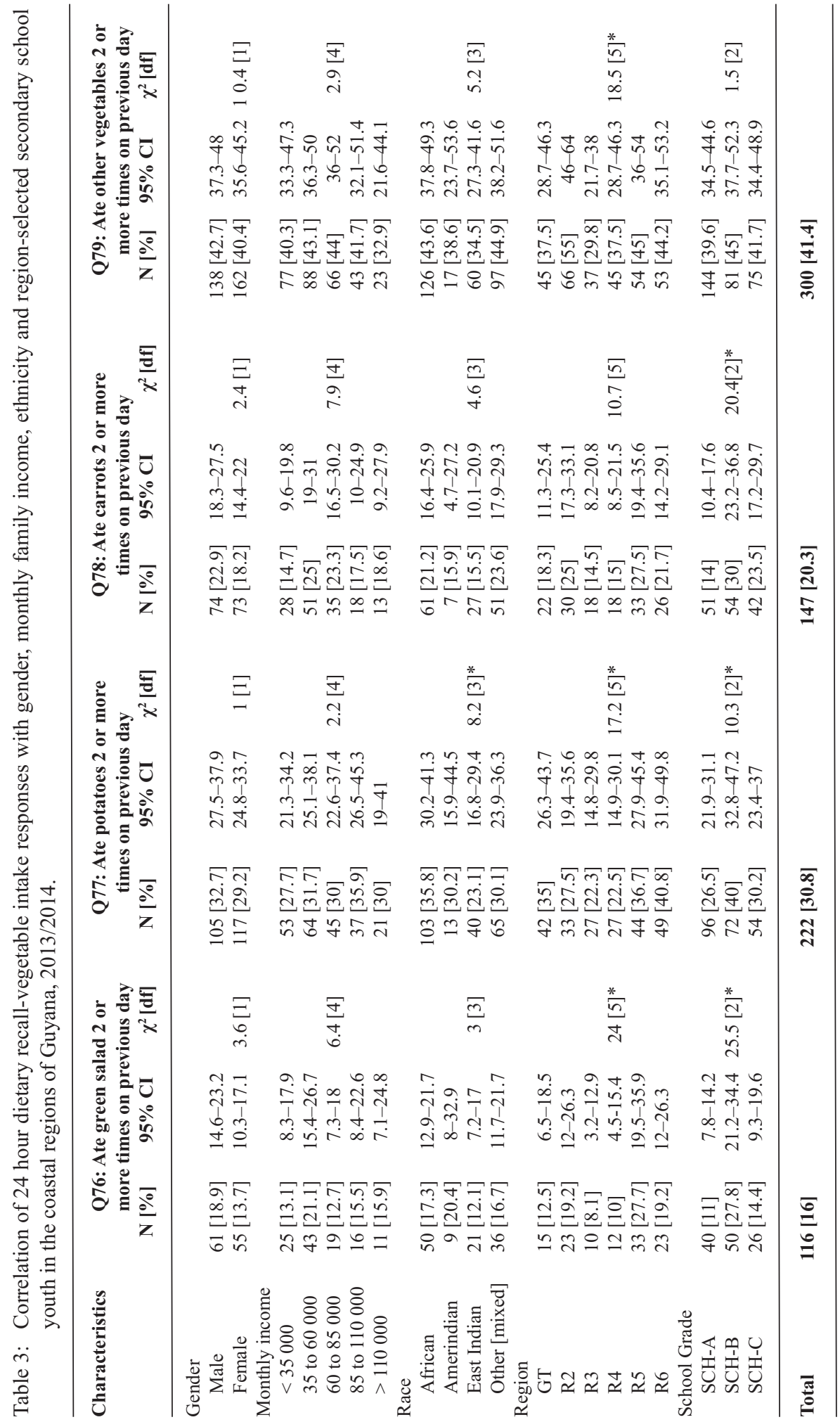


last 12 months. In the same category, the least reported physical activity is frisbee and field hockey. Similarly, Brener et al (C) found that walking was the most common activity and ice hockey the least common sports played by students in the United States of America high schools during the last 12 months.

In the present study, more boys played most of the sports such as baseball/softball, basketball, bike riding, field hockey, football, frisbee, martial arts, skate boarding, soccer, weight lifting and wrestling than the girls during the last 12 months. More girls than boys were involved in dance and skipping rope. These findings are similar to the findings of another study (6).

The recommended intake of vegetables and fruits per day for 11-24-year olds is four servings of vegetables per day for females and five servings of vegetables per day for males and three servings of fruits per day for females and four servings of fruits per day for males (7). In the present study, only $12 \%$ each of assessed students ate two or more cups [approximately equivalent to three or more servings] of vegetables or fruits per day. Olivares et al found (8) that among Chilean school children, intake of fruits and vegetables was low in all age groups, approximately, 2.8 servings per day. In the Florida middle-school youth study, $22.8 \%$ of the students consumed five or more servings of fruits and vegetables per day (5). About three-quarters of the assessed students reported eating French fries or fried potatoes and nearly $40 \%$ reported eating pizza at least once during the past seven days. This finding is consistent with results of other studies $(5,6)$ and where weekly consumption of meals or snacks from fast food restaurants, including French fries or other fried potatoes and pizza was very common among high school students.

The limitations of the study was the small sample size and self-reported nature of data collection. Only 12 schools were covered in this study. These schools were selected based on criteria of school grade, $i e$, one A grade school and one of either B or C grade school from each of selected region. Because the study responses were self-reported, they are subject to reporting bias. Students might over-report or under-report some behaviours for example bringing their own lunch to school from home daily, consuming vegetables, fruits, French fries or snacking from a fast food restaurant etc.

The study recommendations are:

- This study can be done in a larger scale covering all the secondary level public schools across Guyana.

- Further study can be done to explore specific associations of dietary behaviours and physical activity behaviours with baseline variables using regression analysis and odds ratios.

- Need to implement comprehensive physical activity programmes (CPAP) in all secondary schools of Guyana as recommended by CDC.

\section{REFERENCES}

1. Robbins G, Powers D, Burgess S. A fit \& well way of life. New York, USA: McGraw-Hill Companies Inc; 2008: 364

2. Adolescent and School Health [Internet]. Centers for Disease Control and Prevention [retrieved at 2013 Sep 20]. Available from: http://www.cdc.gov/healthyyouth/nutrition/facts.htm

3. Noncommunicable diseases country profiles 2011 - Guyana [Internet]. World Health Organization [retrieved at 2013 Sep 20]. Available from: http://www.who.int/nmh/countries/2011/guy en.pdf

4. Data table of BMI-for-age charts [Internet]. Centers for Disease Control and Prevention [retrieved at 2014 Jul 22]. Available from: http://www.cdc.gov/growthcharts/html_charts/bmiagerev. htm

5. Zapata LB, Bryant CA, McDermott RJ, Hefelfinger JA. Dietary and physical activity behaviours of middle school youth: The youth physical activity and nutrition survey. J Sch Health [Internet]. 2008; 78: 9-18. Available from: http://apps.webofknowledge.com.ezproxy.otago.ac.nz/full_record.do?product $=\mathrm{W}$ OS\&search $\_$mode $=$CombineSearches\&qid $=9 \& S I D=W 1 P M J G k$ m5AOpgf27 jifipage $=5 \&$ doc $=48$

6. Brener ND, Eaton DK, Kann LK, McManus TS, Lee SM, Scanlon $\mathrm{KS}$ et al. Behaviors related to physical activity and nutrition among U.S. high school students. J Adolesc Health [Internet]. 2013; 53: 539-46 Available from: http://www.ncbi.nlm.nih. gov/pubmed/23796969

7. Number of Servings a Day for Teenagers [Internet]. American Academy of Pediatrics; 2003; [retrieved at 2014 Jul 22]. Available from: http://www.healthychildren.org/Documents/tables/Number-of-Servings-a-Day-for-Teenagers.html

8. Olivares S, Kain J, Lera L, Pizarro F, Vio F, Morón C. Nutritional status, food consumption and physical activity among Chilean school children: a descriptive study. Eur J Clin Nutr 2004; 58: 1278-85. 